\title{
Evaluation of risk factors for pressure injuries in home care unit patients.
}

\author{
Mahcube Cubukcu* \\ Department of Family Medicine, Health Sciences University Samsun Education and Research Hospital, Samsun, \\ Turkey
}

\begin{abstract}
The author aimed to evaluate the risk factors for pressure injuries in those receiving home care units. This cross-sectional descriptive study was performed in $\mathbf{7 8 6}$ patients who were served from home care unit between $1^{\text {st }}$ March 2016 and $31^{\text {st }}$ April 2016. Patients' pressure injury was evaluated with Braden risk assessment scale. The mean age of seven hundred eighty six patients was $71.22 \pm 16.23 \mathrm{y} ; \mathbf{5 1 . 3 \%}$ of them were female. In home care unit patients, the pressure injury prevalence is $29.8 \%$. It was observed that in patients who had $11.9 \pm 3.0$ point averages from the Braden risk assessment scale. It was seen the pressure injury evaluation and in patients who had $21.1 \pm 3.4$ point averages it was not seen any evaluation of the pressure injury $(t=14.6, p=0.000)$. In home care patients, the pressure injury prevalence is found in $29.8 \%$ age, having chronic illness, nutrition status are risk factors to pressure injury in home care patients. Patients who were served in home care unit had high risk for pressure injuries. In this respect, in home care patients should be evaluated for pressure injuries.
\end{abstract}

Keywords: Braden, Home care unit, Pressure injury, Patients.

Accepted on August 31, 2018

\section{Introduction}

In accordance with the suggestions of physicians to the patients, the medical examination which embraces the social and psychological consultancy services in his/her home or family environment is provided and on the other hand observation, analysis, treatment, medical care, following and the rehabilitation services are supplied $[1,2]$. This practice in different countries appeals to the needers in a wide range; from those whom had a need for post-operative care, to patients and elders whom need long term care, from the mothers whom newly gave birth to the patients whom can continue to be home-cured, from the patients whom need short-term nursing services to those who wants services such as immunization and laboratory observations in his/her home or workplace. The aims of home care units; to increase the functions of the individuals, contribute for well-being of the services area to become in optimal level, the service area by preventing the individuals' hospitalization or institutionalization ensure them to stay in his/her home [3].

Pressure injuries are defined as localized injury to the skin and underlying tissue that occur over bony prominences because of pressure or pressure in combination with shear, whereas skin failure is defined "as an event in which the skin and underlying tissue die due to the hypoperfusion that occurs concurrent with severe dysfunction or failure of other organ systems" [4].
The pressure injuries are localized tissue damage which is consisted with, in skin/subcutaneous tissue, in bone spurs with pressure and/or shear (laceration)/friction/medical stuff [5].

The pressure injury prevalence changes between 3\%-66\%. The pressure sore prevalence change from $0-29 \%$ in those who gets home care unit [6]. Pressure injuries are serious health problem that increases the risk of illness and death extends the hospitalization duration and requires high treatment cost. As in case of many other diseases, a good quality care also has a high importance for prevention and treatment of the pressure injury. It reduces the quality of life of the patients and their relatives [7]. Pressure injuries extend the hospitalization duration [8,9]. It increases the cost of healthcare services [9]. It increases morbidity and mortality by four or five times [10]. It doubles the nasocomial infection risk. Brown et al. reported that the patients that have newly-emerging pressure injury in the long term care center, six months of mortality rate was $67 \%$ [5].

In development of pressure injury, in individual plays different preparatory risk factors. Factors arising from the patients such as pressure, friction, physical inactivity, bacterial contamination, due to fecal/urinary incontinence dampness of the skin, loss of sense, loss of motor (muscles of movements), old age, high fever, peripheral vascular disease, malnutrition cause the occurrence of pressure injury disease $[11,12]$.

The main pathology of the development of pressure injury is the cease of blood flow depending on the pressure on affected areas and hypoxia [13]. Disruption of capillary circulation due 
to pressure pulls the trigger for occurrence of the sore by causing hypoxia [14].

In home care patients, risk assessment should be carried out on first contact, documented and reviewed weekly or as the patient's condition or circumstances change. The risk assessment score, combined with the holistic patient assessment, should ensure that the correct support surface and interventions are implemented [15].

\section{Materials and Methods}

A cross-sectional descriptive methodology was used for this study. The study was conducted between $1^{\text {st }}$ March 2016 and $31^{\text {st }}$ April 2016 in Samsun province. The patients who were served from home care unit were visited by the Health Sciences University Samsun Education and Research Hospital home care team. One doctor visited nine or ten patients a day in a month time. A questionnaire form which includes sociodemographic attributes was filled to the 786 patients over 18 year-old whom had pressure injury whom accepted this study and received informed consent. These include age, gender, civil, social security, educational status, chronic illnesses, nutrition, state of consciousness, dependent on the bed, pressure injury existence and stage were questioned. Braden risk assessment scale is implemented to the patients. The Braden risk assessment scale was developed by Braden and Bergstrom in 1987 with the aim of to determine pressure injury risk. The first reliability and validity of this scale was made by Oguz in 1997. In 1998, the reliability and validity of the Braden risk assessment scale were made by Pınar and Oguz and reliability and validity were determined high. Developed Braden risk assessment scale which takes as a basis the risk factors of the patients whom had been given home care is made of from 6 subscale. These are; sentimental perception, humidity, activity, mobility, nutrition, friction and position. The total score is between 6 and 23, and a low total score indicates a high risk for pressure ulcer. This scale is very reliable for the determination of patients which have great risks for pressure injury [2].

Health Sciences University Samsun Education and Research Hospital Clinical Research Ethical Committee approval was granted for the study.

\section{Statistical analysis}

Statistical analysis was evaluated using SPSS software version 20.00. Results are expressed as mean and standard deviation (SD). The Pearson's Chi-square test and Student t-test were used in the evaluation of the data. Statistical significance was accepted at $\mathrm{p}<0.05$.

\section{Results/Observations}

Of the 786 patients who participated in this study, 51.3\% $(n=403)$ female and $48.7 \%(n=383)$ male. The mean age of the patients was $71.22 \pm 16.23$ y (min: $18 \max$ : 93). $66.4 \%$ $(n=522)$ of the patients were married, 32.5\% $(n=255)$ of the patients graduated from primary school (Table 1). $31.4 \%$ $(n=247)$ of the patients had a chronic disease. $29.8 \%(n=236)$ of the patients had pressure injury (Table 2). The localization of pressure sore was observed: in sacrum region $96(40.8 \%)$, trochanter $45(18.9 \%)$, ankles $32(13.5 \%)$, vertebra $10(4.3 \%)$, Achilles $9(4.1 \%)$, scapula $7(3.1 \%)$, ears $6(2.9 \%)$, humerus 6 $(2.7 \%)$, femoral $(1.4 \%)$, elbow $2(1.7 \%)$. When the pressure sore stages were examined it was observed that stage I was 74 (31.2\%), stage II was $104(44.2 \%)$, stage III was $44(18.8 \%)$ and stage IV was $14(5.8 \%)$. According to the results of the patients in Braden risk assessment scale, it was determined that there were 314 (39.9\%) patients who had no risk (19-23) in terms of pressure injury development, $202(25.7 \%)$ patients were on the verge of a risk (15-18), $143(18,2 \%)$ had moderate level of risk (13-14), 82 (10.4\%) patients had high risk (10-12) and 45 patients had very high risk (5.8\%) (9 and below).

It was found statistically significant relation between the pressure injury and the level of consciousness (Table 3) $(p<0.005)$. Nutritional status and the risk of pressure injury development were statistically significant $(\mathrm{p}<0.005)$.

The mean age of patients with pressure injury was $74.22 \pm$ $14.31 \mathrm{y}$, the age of patients that have not had the pressure injury was $70.04 \pm 12.42(\mathrm{t}=3.2, \mathrm{p}=0.001)$. It is observed that in the patients whom mean points from the Braden risk assessment scale were $11.9 \pm 3.0$ the development of pressure injury occurred, and in the patients whom mean points from Braden risk assessment scale were $21.1 \pm 3.4$ it did not occurred pressure injury $(\mathrm{p}<0.001)$.

Table 1. The distribution of patients by socio-demographic characteristics $(n=786)$.

\begin{tabular}{lll}
\hline Descriptive characteristics & Number & Percent \\
\hline Age $(\mathrm{y})$ & 110 & 14 \\
\hline $18-41$ & 129 & 16.4 \\
\hline $42-65$ & 387 & 49.2 \\
\hline $66-90$ & 160 & 20.4 \\
\hline$>90$ & & \\
\hline Condition & 522 & 66.4 \\
\hline The married & 124 & 15.8 \\
\hline Single & 140 & 17.8 \\
\hline Divorced/widow & & \\
\hline Education status & 96 & 12.2 \\
\hline Not literate & 101 & 16.4 \\
\hline Literate & 255 & 32.5 \\
\hline Primary high school & 145 & 18.4 \\
\hline Middle school & 121 & 15.4 \\
\hline High school & 68 & 5.1 \\
\hline University & & \\
\hline Social security & & \\
\hline
\end{tabular}

Social security 


\begin{tabular}{lll}
\hline Yes & 766 & 97.4 \\
\hline No & 20 & 2.6 \\
\hline Diagnosis & 215 & 27.3 \\
\hline Alzheimer's & 203 & 25.8 \\
\hline Cerebrovascular disease & 95 & 12.1 \\
\hline Parkinson's & 149 & 18.9 \\
\hline Oncological diseases & 124 & 15.9 \\
\hline
\end{tabular}

\begin{tabular}{lll}
\hline Stupor & 32 & 5.5 \\
\hline Conscious off & 43 & 4 \\
\hline Dependency & & \\
\hline Fully dependent & 490 & 62.4 \\
\hline Semi-dependent & 269 & 34.2 \\
\hline Independent & 27 & 3.4 \\
\hline Pressure injury & & \\
\hline Yes & 236 & 29.8 \\
\hline No & 552 & 70.2 \\
\hline Chronic disease & & \\
\hline Yes & 247 & 31.4 \\
\hline No & 539 & 68.6 \\
\hline
\end{tabular}

Table 2. The distribution of the patients by the preparatory characteristics of pressure injury formation $(n=786)$.

\begin{tabular}{lll}
\hline Descriptive characteristics & Number & Percent \\
\hline Nutrition status & & \\
\hline Oral & 706 & 89.8 \\
\hline Nasogastric & 25 & 3.2 \\
\hline PEG (gastrostomy) & 55 & 7 \\
\hline The status of consciousness & & \\
\hline Conscious & 711 & 90.5 \\
\hline Stupor & 32 & 5.5 \\
\hline Conscious off & 43 & 4 \\
\hline Dependency & & \\
\hline Fully dependent & 490 & 62.4 \\
\hline Semi-dependent & 269 & 34.2 \\
\hline Independent & 27 & 3.4 \\
\hline Pressure injury & & \\
\hline Yes & 236 & 29.8 \\
\hline No & 552 & 70.2 \\
\hline Chronic disease & 539 & 68.6 \\
\hline Yes & & \\
\hline No & & \\
\hline
\end{tabular}

Table 3. The distribution of formation of pressure injury by age, gender, having chronic disease, the status of consciousness nutrition status in home care patients.

\begin{tabular}{lll}
\hline Descriptive characteristics & Number & Percent \\
\hline Nutrition status & & \\
\hline Oral & 706 & 89.8 \\
\hline Nasogastric & 25 & 3.2 \\
\hline PEG (gastrostomy) & 55 & 7 \\
\hline The status of consciousness & & \\
\hline Conscious & 711 & 90.5 \\
\hline
\end{tabular}

\section{Discussion}

This study's goals were to evaluate risk factors for pressure injuries in those receiving home care units.

In the study of Akturk et al. found the pressure injury prevalence was $23.8 \%$ [16]. In our study, the pressure injury prevalence was $29.8 \%$. The reason of this can be because of the high percentage of our patients were fully dependent on the bed.

In the study of Sahin et al. the mean age of patients was 80 years [12]. In our study, the mean age of patients was $71.22 \pm$ $1.83 \mathrm{y}$.

In our study, it was determined that pressure injury was mostly at the stage II (44.2\%). In the study of Ozgenel et al. have shown the reason of that as a rehabilitation and a longer process of transition to daily life due to the reasons such as low educational level and economic problems [17]. In the study of Lepisto et al. stated in a study conducted in eleven hospitals in Finland that the highest pressure injury prevalence was at the stage II $(40 \%)$ [18].

In our study, pressure injury was the most frequent in sacrum $(40.8 \%)$. In the study of Uzun et al. it was observed that the pressure injury was the most frequent in sacrum [2].

In our study, it was found that the patients whom were the most stupor conscious state developed pressure injuries $(65.6 \%)$. In the study of Inan et al. found that the patients whom were the most stupor conscious developed pressure injuries (66.7\%) [7]. In the same way, it has also been determined in the study of Lepisto et al. that the more consciousness level was deteriorated the pressure injury was developed [18].

In the study of Horn et al. when they examined the patients that had developing pressure injury it was also observed that the most frequent diagnosis was hypertension (38\%) [3]. In our study, there was also an increase in the pressure injury prevalence in patients with chronic illness. 
In the study of Uzun et al. found that $32.3 \%$ of the patients were in the risk group in terms of pressure injuries development [2]. According to the results of the Braden risk assessment scale in our study, $34.4 \%$ of our patients were in the risk group.

In the study of Katran found that $31.4 \%$ of the patients in the age group of $75 \mathrm{y}$ and over formed pressure injury and there was a significant correlation between the age and pressure injury development $(p=0.001)$ [19]. In our study, we determined that $55.9 \%$ of patients at the age of $65 \mathrm{y}$ or more developed pressure injury and that in elder ages, the rate of pressure injury development was increased $(p=0.001)$. In the study of Inan et al. also showed that the mean age of the patients who are in a risk of pressure injury development (56.3 \pm 16.5 ) is elder than the mean age of the patients whom have not has a pressure injury $(48.5 \pm 16.5)$ and the relation between them was significant $(\mathrm{p}=0.000)$ [7]. According to the Braden risk assessment scale the average age of the patients whom are in a risk of pressure injury development (74.22 \pm 14.31$)$ was higher than the average age of patients whom in a risk of pressure injury development $(70.04 \pm 12.42)$ and the correlation between them was significant $(\mathrm{p}=0.001)$.

In the study of Inan et al. Braden risk assessment scale it was observed that the score $(11.7 \pm 3.1)$ was lower in those patients whom were diagnosed with pressure injury. The Braden risk assessment scale score was higher $(20.1 \pm 3.6)$ in those who had not had diagnosed with pressure injury and the relation between them was found to be significant $(p=0.000)$ [7]. In our study, patients who were diagnosed with pressure injury had lower scores on the Braden risk assessment scale (11.9 \pm 3.0$)$, we found that the Braden risk assessment scale score was higher $(21.1 \pm 3.4)$ in the patients whom had not had pressure injury and we determined there was a significant correlation between them $(t=14.6, p=0.000)$.

Health care is very important in major diseases, especially in home care patients. In home care patients, the pressure injury prevalence frequency is $29.8 \%$. Age, having chronic illness, nutrition status are risk factors to pressure injury in home care patients. The Braden risk assessment scale should apply to home-care patients, and the formation of pressure injury should be avoided.

\section{Acknowledgments}

Authors thank all participants for their cooperation in this study.

\section{References}

1. Lyder $\mathrm{CH}$. Pressure ulcer prevention and management. Ann Rev Nurs Res 2002; 2: 25-62.

2. Uzun O, Tan MA. Prospective, descriptive pressure ulcer risk factor and prevalence study at a university hospital in Turkey. Ostomy Wound Manag 2007; 53: 44-56.

3. Horn SD, Bender SA, Bergstrom N, Cook AS, Ferguson ML. Description of the national pressure ulcer long-term care study. Am Geriatr Soc 2002; 50: 1816-1825.
4. Dellmore B, Cox J, Rolnitzky L, Chu A, Stolfi A. Differentiating a pressure ulcer from acute skin failure in the adult critical care patient. Adv Skin Wound Care 2015; 28 : 514-524.

5. National Pressure Ulcer Advisory Panels Updated Pressure Ulcer Staging System (NPUAP). Advances Skin Wound Care 2007; 20: 269-274.

6. Niezgoda JA, Eastman SM. The effective management of pressure ulcers. Adv Skin Wound Care 2006; 19: 3-15.

7. Inan DG, Oztunc G. Prevalence of pressure sores in patients hospitalized in Turkey: a sample from a University Hospital. JQWCN 2012; 39: 409-413.

8. Kumar S, Wong PF, Leaper DJ. What is new in wound healing? Turk J Med S 2004; 147-160.

9. Zhan C, Miller MR. Excess length of stay, charge, and mortality attributable to medical injuries during hospitalization. JAMA 2003; 290: 1868-1874.

10. Ducker A. Pressure ulcers: assessment, prevention and compliance. Case Mana 2002; 13: 61-65.

11. Lyman V. Successful heel pressure ulcer prevention program in a long term-care setting. J Wound Continence Nurs 2009; 36: 616-621.

12. Sahin S, Akcicek F. Elderly patient prevention, diagnosis and treatment. Elder J Acad Geriatr 2009; 1: 139-146.

13. Ay FA. Ulcer and ulcer care. Basic nursing concepts, principles, practices (1st Edn.). Istanbul Medical İstanbul Turkey 2007; 5-10.

14. Elkin MK, Perry AG, Potter PA. Nursing interventions \& clinical skills (3rd Edn.). USA 2003.

15. Benbow M. Guidelines for the prevention and treatment of pressure ulcers. Nursing Standard 2006; 20: 42-44.

16. Akturk A, Atmaca E, Zengin S. The prevalence and clinical features of pressure ulcers in patients receiving home care in Kocaeli province. Turkderm 2010; 44: 128-131.

17. Ozgenel GY, Kahveci R, Akin S, Ozbek S, Ozcan M. Our treatment principles and consequences in pressure sores. $\mathrm{J}$ Uludag Univ Med Fac 2002; 28: 325-327.

18. Lepisto M, Erikson E, Hietanen H, Asko-Seljavaara S. Patient with pressure ulcers in Finnish hospitals. Int $\mathrm{J}$ Pract 2001; 7: 280-287.

19. Katran $\mathrm{BH}$. Investigation of the risk factors affecting the development of a scarce injury and scarred injury in a surgical intensive care unit. JAREN 2015; 21: 8-14.

\section{*Correspondence to}

Mahcube Cubukcu

Department of Family Medicine

Health Sciences University Samsun Education and Research Hospital

Turkey 